\title{
The effects of gregarine parasites, body size, and time of day on spermatophore production and sexual selection in field crickets
}

\author{
Marlene Zuk * \\ Museum of Zoology, University of Michigan, Ann Arbor, MI 48109, USA
}

Received November 13, 1986 / Accepted March 13, 1987

\begin{abstract}
Summary. In laboratory experiments measuring the rate of spermatophore production in the field crickets Gryllus veletis and $G$. pennsylvanicus by confining single males with a conspecific female, $0-10$ spermatophores were produced by each male within $24 \mathrm{~h}$. The number of spermatophores produced was unrelated to a male's body size, but was significantly negatively correlated with the natural levels of gregarines, a protozoan gut parasite, in the males. Spermatophore production in the laboratory peaked between 0600 and $1000 \mathrm{~h}$, as did the proportion of courtship songs given by male crickets in the field, suggesting that mating may occur more frequently in the morning. When single males were placed in jars with two conspecific females, $49 \%$ transferred spermatophores to both females, whereas $51 \%$ of males only gave spermatophores to one of the females. The results support the hypothesis that parasites are important in sexual selection, and are used to propose a new interpretation of post-copulatory guarding in crickets.
\end{abstract}

\section{Introduction}

Although studies of mate choice in insects frequently concentrate on the process of attracting a mate, sexual selection can continue to act after a male and female have formed a pair but before the eggs are laid and offspring produced. In many insect species, lengthy or repeated copulations are required for fertilization of the female's clutch (Gwynne and Morris 1983; Thornhill and Alcock 1983); variation in the duration of copulation, the

\footnotetext{
* Current address: Department of Biology, University of New Mexico, Albuquerque, NM 87131, USA
}

ability to fend off intruders, or the timing of insemination to assure sperm precedence can all be reflected in the reproductive success of a particular individual (Smith 1984).

Female field crickets commonly mate more than once with the same or different males. A study of Acheta domesticus and Gryllus integer showed that, in the first species, multiply mated females produce significantly more offspring than singly mated females, and in the second species that $50 \%$ of singly mated females did not reproduce at all (Sakaluk and Cade 1980). The decreased fecundity may be attributed in part to a tendency for the female, after she has received a spermatophore, to attempt to eat or remove it, often before it has drained all of its sperm into her body (Sakaluk and Cade 1980). Males of several cricket species have distinct post-copulatory behaviour patterns suggested to function both to prevent such removal and to keep the female from leaving the male and perhaps receiving spermatophores from other males (Alexander 1961; Loher and Rence 1978). The ability to replace spermatophores might therefore be expected to increase male reproductive success.

This study examined male ability to produce multiple spermatophores in light of a theory proposed by Hamilton and Zuk (1982) about the role of parasites and disease in mate choice and sexual selection. The interactions between host alleles for susceptibility or resistance to parasites on the one hand, and a parasite's alleles for virulence in the host on the other, are particularly interesting from an evolutionary standpoint, because they are often frequency-dependent. These interactions readily produce stable limit cycles in the gene frequencies of both species (Hamilton 1982; Eshel and Hamilton 1984). If resistance to pathogens is genetically based, a common situation in insects (Anderson 
and May 1981), such dynamic behaviour implies that females choosing males with alleles resistant to whatever parasites are prevalent in the population continue to get heritable gains in fitness for their offspring, even if selection has been continuing for many generations (Hamilton and Zuk 1982). Sexually-selected characters are thus predicted to reflect health of the potential mate.

I also examined the relevance of multiple spermatophore production to cricket mating behaviour under field conditions. Rapid spermatophore replacement is especially important if mating and spermatophore production are concentrated at a particular time of day. Observations by French (1986) on G. integer, G. veletis and G. pennsylvanicus suggest that a burst of mating occurs in the morning, even though a majority of calling takes palce at night, or (in the case of $G$. integer) just before sunrise. I monitored the diel distribution of calling and courtship songs in a field population of $G$. pennsylvanicus, and then experimentally examined the diel periodicity of spermatophore production to determine if any peaks in spermatophore production in the laboratory were coincident with peaks in mating frequency observed in the field.

If females wait until morning to mate, two or more females may be attracted to the same male, and that male must provide spermatophores to all of the accumulated females if he is to achieve maximum mating success (Zuk, unpublished observations). An additional experiment, therefore, evaluated a male's ability to provide spermatophores to both of two females left with him for $12 \mathrm{~h}$.

\section{Methods}

All of the research was done at the University of Michigan Biological Station near Pellston, Michigan in Cheboygan County during the summers of 1983-1985. G. veletis were collected as adults in old fields, roadsides, and around buildings; $G$. pennsylvanicus were collected as both nymphs and adults in similar habitats, and some experiments were performed using adults reared in the laboratory. Unless stated otherwise, all crickets were kept on a diet of lettuce and dry cat food in a laboratory at approximately $22^{\circ} \mathrm{C}$ under a light: dark schedule of approximately 14:10, similar to that in nature.

$G$. veletis and $G$. pennsylvanicus are temporally separated species with almost identical appearance and behaviour. G. veletis overwinter as late-instar nymphs, and in northern Michigan, males sing from late May until late July; G. pennsylvanicus overwinter as eggs, with adults present from early August until autumn frosts (Alexander and Meral 1967; Lloyd and Pace 1975). In both species, males sing from cavities under rocks and boards, outside of burrows, and in leaf litter. When a female has been attracted to a male's call, he switches to a quieter courtship song, and copulation, consisting of the transfer of a spermatophore into the female's genital opening, may then follow (Alexander 1961).

\section{The Parasites}

Gregarines (Class Sporozoa, Order Gregarinida) are gut parasites of many invertebrates, developing from spores ingested by the host (Kudo 1954). Spores pass into the host fore- and midgut, where they attach to the epithelial wall and feed on the material present in the gut lumen. After a period of growth, the mature gregarine, called a trophozoite, detaches from the gut wall and joins with another trophozoite. The pair mates, and coalesces into a walled cyst that is passed out with the host faeces. Damage to the host can occur when large numbers of gregarines block passage of food across the gut, or when they attach in such numbers that the epithelium is eroded, allowing passage of pathogenic bacteria and viruses into the host haemocoel (Bucher 1959). Each cyst may release hundreds of spores after an incubation period of several days (Kudo 1954), and infection levels in the host may be monitored by examining faeces for eliminated cysts (Zuk, unpublished).

While some authors have regarded gregarines as harmless commensals (Kudo 1954), experiments on carpet beetles (Dunkel and Boush 1969), grasshoppers (Harry 1970), and crickets (Zuk 1987a, b) have shown that infected individuals have delayed development, decreased longevity, and lighter weight than uninfected insects, particularly under suboptimal environmental conditions.

\section{Diel distribution of calling and courtship songs}

To determine how mating, as indicated by courtship songs, was distributed throughout the day and night, I walked slowly through an area on the field station approximately $150 \mathrm{~m} \times$ $50 \mathrm{~m}$ at about $1000 \mathrm{~h}, 1800 \mathrm{~h}$, and $2400 \mathrm{~h}$ each day between 25 August and 3 September 1983. The habitat was sandy roadside and weeds, with several cabins and sheds alongside the road. The positions of all singing male $G$. pennsylvanicus were flagged and their location and song type (calling or courtship) noted. The two types of song are easily distinguished by ear (Alexander 1961).

\section{Periodicity in spermatophore production}

If mating and spermatophore production are concentrated in time, rather than evenly distributed throughout the day, rapid spermatophore replacement is more advantageous for males. This experiment consisted of two trials designed to test the hypothesis that a peak in spermatophore production occurs in the morning. In both trials, 24 male $G$. pennsylvanicus each held with a single female in a glass jar, were examined for the presence of a spermatophore in the genital chamber by gently opening the genital flap and probing with fine forceps; any spermatophores so detected were removed with the forceps. Spermatophores were removed every $2 \mathrm{~h}$ for $8 \mathrm{~h}$, which constituted a depletion; the males were checked again, and spermatophores removed, $8 \mathrm{~h}$ after the last depletion and once more $16 \mathrm{~h}$ after the last depletion. In one trial, the depletion occurred in the morning and the two checks were made in the evening at $2230 \mathrm{~h}$ and the following morning at $0630 \mathrm{~h}$, respectively, while in the second trial, depletion in the evening was followed by checks the following morning at $0630 \mathrm{~h}$ and in the afternoon at $1430 \mathrm{~h}$. Thus, those males in the first case had $16 \mathrm{~h}$ between depletion and a morning spermatophore check, whereas males in the second case had $8 \mathrm{~h}$ between depletion and the morning spermatophore check; if spermatophores are produced more frequently in the morning under both conditions, spermatophore production itself appears to have a peak in the morning. 


\section{Relation between spermatophore production and degree of infection evidenced in excreted cysts}

In a preliminary test of the hypothesis that spermatophores are more likely to be produced when crickets are relatively unburdened by gregarines, 15 male $G$. veletis and 18 male $G$. pennsylvanicus were fed ad libitum and held individually in the laboratory in $70 \mathrm{ml}$ plastic vials with foam plugs. All G. veletis were collected as adults early in June, while $G$. pennsylvanicus males were laboratory-reared. The material in the bottom of each vial was checked under a dissecting microscope every other day for the level of gregarine cyst infection in the faeces and for the presence or absence of a discarded spermatophore. Cyst infection levels were graded as follows:

none: zero cysts visible;

light: faecal pellets containing 1-2 cysts each; moderate: $2-10$ cysts/faecal pellet;

heavy: $>10$ cysts/faecal pellet, with faeces consisting almost entirely of gregarine cysts.

Cyst excretion levels were ranked rather than counted because the large variation in cyst size, as well as in the number of faecal pellets produced per individual, made comparison of actual numbers of cysts less meaningful. The crickets were held until their death, for an average of 14 measurements in $G$. veletis and 15 measurements in $G$. pennsylvanicus. Individuals which died after five measurements or fewer were excluded from the analysis. G. veletis were experimentally infected with gregarines twice, eight and 16 days after the start of observations, while $G$. pennsylvanicus were infected once, seven days after the start of observations. Infection was accomplished by feeding each of the crickets a $5-10 \mathrm{~mm}^{2}$ piece of lettuce that had been inoculated with 3-5 infective (sporulated) cysts. This dose results in moderate to heavy levels of gregarines within the gut in a week to 10 days (Zuk, unpublished).

\section{4-h spermatophore production}

To examine maximum spermatophore production over a $24 \mathrm{~h}$ period, and its correlation with body size and parasite load, 24 sexually mature male $G$. veletis and 21 sexually mature $G$. pennsylvanicus males, all field-collected, were each weighed to the nearest 0.001 gram and placed in an individual 4.21 glass jar with a $1-2 \mathrm{~cm}$ layer of vermiculite on the bottom and a cardboard shelter. One conspecific adult female cricket was also placed in the jar.

Every two hours for $24 \mathrm{~h}$, males were examined for spermatophores as described earlier, and each female was examined for spermatophores attached to the genital opening, which were also removed. At each 2 -h examination, each female was moved into the next male's jar. This rotation helped to prevent bias arising through differential receptivity or attractiveness of individual females. Total spermatophores produced were tallied as the number removed from the male, plus the number he transferred to females. No food was provided in these experiments.

\section{Short-term spermatophore production}

To examine the rate at which spermatophores are replaced in $2 \mathrm{~h}$ and to see if the correlation between gregarine load and spermatophore production was present within a short time, each of 24 male $G$. pennsylvanicus was placed with two females and checked for spermatophores every half hour for $2 \mathrm{~h}$. Because of the short duration of the experiment, females were not rotated among the males, but spermatophores were removed from males and females as in the previous experiments.
At the conclusions of each spermatophore production experiment except the preliminary one monitoring cyst excretion, males were frozen and dissected to determine gregarine parasite loads. The few individuals with guts that were extremely abnormal in appearance (i.e., shrunken or filled with chitinized objects), or those crickets harbouring horsehair worms (Nematomorpha), were excluded from analysis for gregarines. The gregarines present in the gut were ranked according to the following scale:

1) none: no cysts or trophozoites present;

2) very light: $1-3$ cysts or trophozoites;

3) light: 4-10 cysts and/or trophozoites;

4) moderate: approximately $11-30$ cysts and/or trophozoites;

5) heavy: $31-50$ cysts or trophozoites;

6) very heavy: $>50$ cysts and trophozoites; gut almost occluded by gregarines.

Discrete categories were employed instead of quantitative counts of parasites because freezing and thawing the crickets occasionally ruptured gregarine membranes, making cell boundaries of individual trophozoites difficult to distinguish. The amount of moisture and digested food in the gut also affected the integrity of the protozoa.

\section{Spermatophore transfer to multiple females}

To study variance in spermatophore production in a more natural context, each of $37 \mathrm{G}$. pennsylvanicus males was left with two individually marked females in a 4.21 glass jar with a layer of vermiculite and a cardboard shelter. To ensure receptivity of the females, all females were deprived of contact with males for at least two days before the start of the experiment. Every $2 \mathrm{~h}$ for $12 \mathrm{~h}$, the females were examined for attached spermatophores, but any spermatophores found were left attached and their condition (old and brown or recently formed and opaque white) noted so that recency of attachment could be judged.

\section{Results}

\section{Diel distribution of calling and courtship songs}

Song data from 26 flagged male positions were obtained over the 10 days. A total of 135 calling songs and 24 courtship songs was noted. The calling songs were heard mainly at night, but $71 \%$ of the courtship songs were heard in the morning, $21 \%$ in the afternoon, and only $8 \%$ at night. Temperatures during the observation period were well within the crickets' tolerance range (Alexander and Meral 1967). Contingency analysis shows a highly significant departure from expected frequencies, given the null hypothesis that the time of day a song is heard is independent of whether it is a calling or courtship song (G statistic $=13.72, P<$ 0.001 ).

\section{Periodicity in spermatophore produciton}

These trials had two major results. First, gregarine levels were significantly negatively correlated with spermatophore production in both experimental 

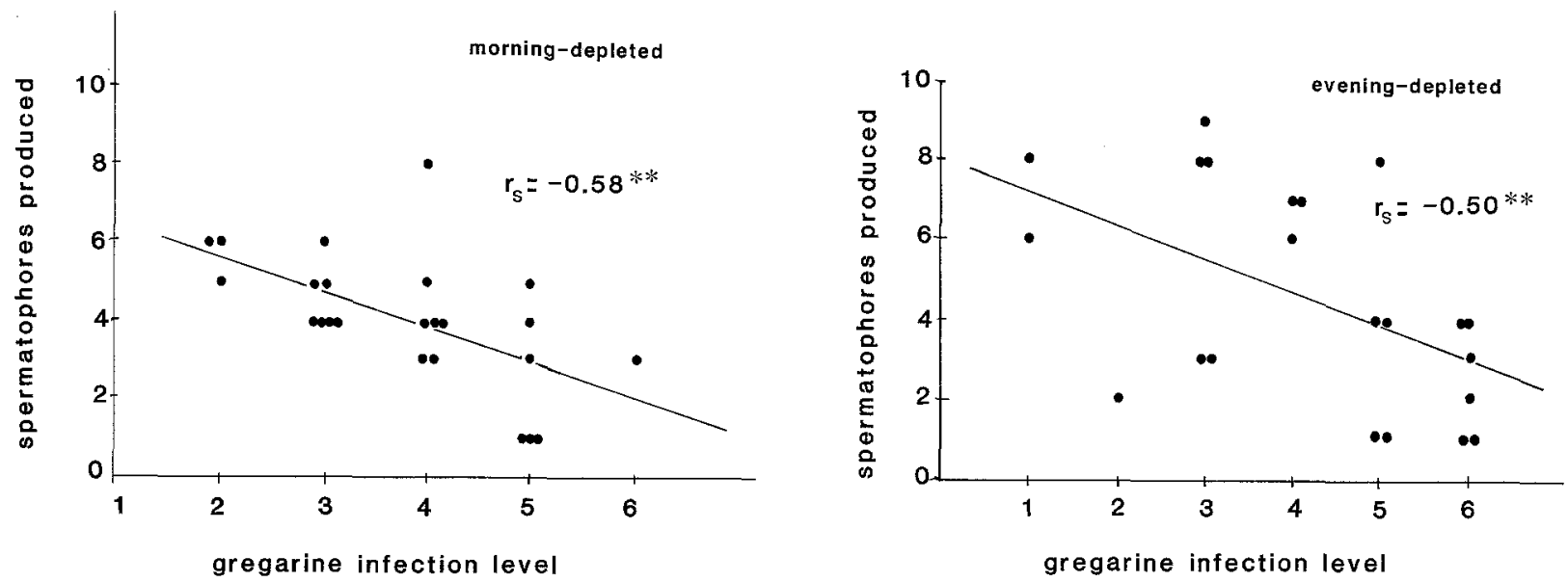

Fig. 1. Number of spermatophores produced by G. veletis harbouring different levels of gregarine infection in two trials of $32 \mathrm{~h}$ each, with 6 examinations for spermatophores in each trial. Left plot is of spermatophore production in morning-depleted males; right plot is of spermatophore production in evening-depleted males. ${ }^{* *} P<0.01$, Spearman rank correlation

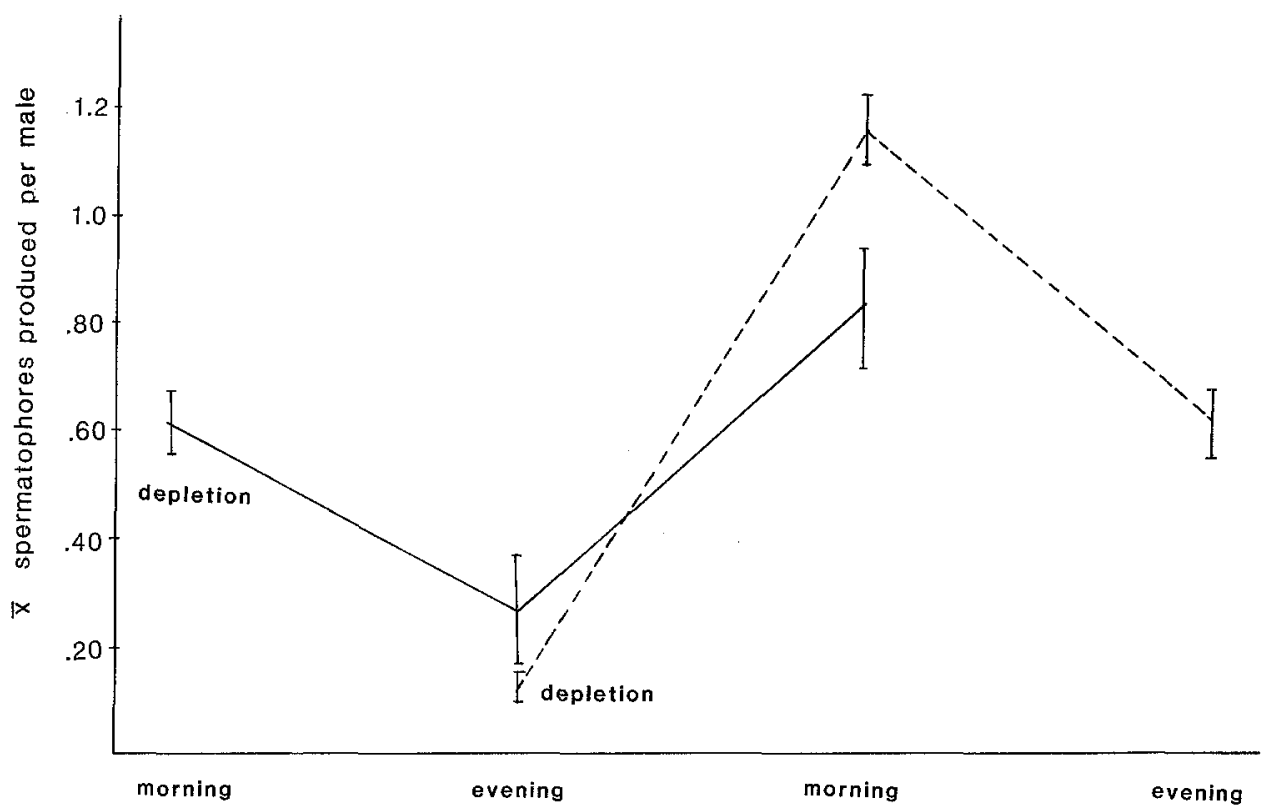

Fig. 2. Spermatophore production at time of last depletion, morning and evening in G. pennsylvanicus. Eight hours elapsed between all sampling periods in both experiments

treatments (Fig. 1, $P<0.01$ in both experiments). Second, although the crickets in the trial with the depletions in the afternoon produced more spermatophores overall, both groups produced significantly more spermatophores in the morning than in the evening (Fig. 2; Mann-Whitney $U=172$ for morning-depleted males, 170 for evening-depleted males, $P<0.001$ in both cases). When depletion was performed in the morning, only $25 \%$ of all males produced spermatophores eight hours later, in the evening. Depletion in the late afternoon and early evening, however, resulted in $83 \%$ of the males producing spermatophores eight hours later, in the early morning.
Relation between spermatophore production and degree of infection evidenced in excreted cysts

In both cricket species, for all individuals pooled, spermatophores were found significantly more frequently on days when cyst excretion was light or zero than when cyst excretion was moderate or heavy (chi-square test for contingency; Table 1).

\section{4-h spermatophore production}

During the $24 \mathrm{~h}$ survey, male G. veletis produced an average of $4.40 \pm 0.50$ (SE) spermatophores, with a range of $0-9$. Male $G$. pennsylvanicus pro- 
Table 1. Gregarine cyst levels in faeces of male G. veletis and G. pennsylvanicus on days when spermatophores were present or absent

\begin{tabular}{llll}
\hline Status of spermatophore & \multicolumn{2}{l}{$\begin{array}{l}\text { Gregarine infection level } \\
\text { in faeces }\end{array}$} \\
\cline { 2 - 3 } & None & Light & $\begin{array}{r}\text { Moderate } \\
\text { and heavy }\end{array}$ \\
& & & \\
\hline G. veletis $n=15$ & & & 4 \\
Spermatophore present & 14 & 13 & 64 \\
Spermatophore absent & 38 & 73 & \\
G. pennsylvanicus $n=18$ & & & \\
Spermatophore present & 29 & 29 & 10 \\
Spermatophore absent & 65 & 29 & 27 \\
\hline
\end{tabular}

"Moderate" and "heavy" categories are lumped because of the small number of observations in those cells. See text for details of gregarine cyst infection levels

$\chi_{2}^{2}=10.20$ for $G$. veletis, $P<0.01 ; \chi_{2}^{2}=7.31$ for $G$. pennsylvanicus, $P<0.05$ )

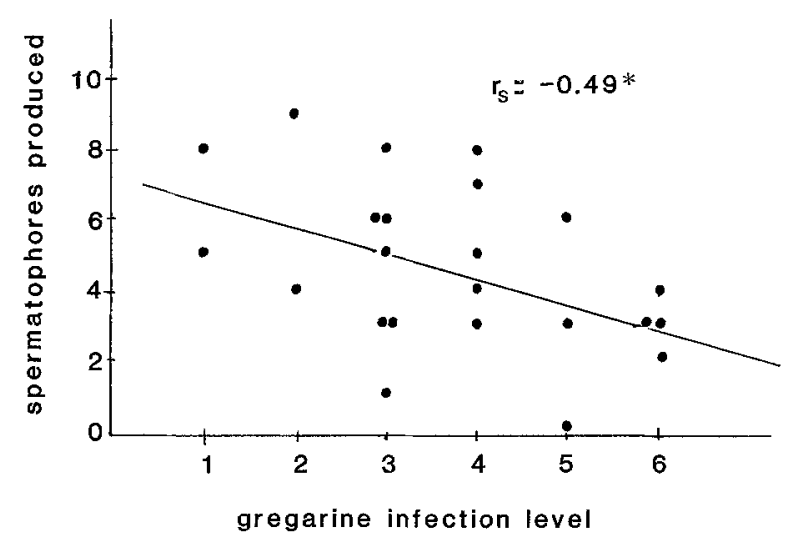

Fig. 3. Number of spermatophores produced in $24 \mathrm{~h}$ by fieldcollected $G$. veletis with different levels of naturally occurring gregarine infections. Infection levels increase in severity with increasing number; see text for detailed description. ${ }^{*} P<0.05$, Spearman rank correlation

duced an average of $5.14 \pm 0.54$ spermatophores, with a range of $1-10$. Females typically only had attached spermatophores for the first three or four measurements, but spermatophores continued to be removed from some males until the end of the experiment.

Body weight was not significantly correlated with spermatophore production in either species (Spearman rank correlation coefficient $=0.29$ for $G$. veletis, -0.22 for pennsylvanicus; $P>0.05$ ). Gregarine levels, however, were significantly negatively correlated with the total number of spermatophores a male produced in $G$. veletis (Fig. 3, $P<$ 0.05 ). This correlation was not significant in $G$. pennsylvanicus $\left(r_{s}=-0.30, P=0.188\right)$. Inspection

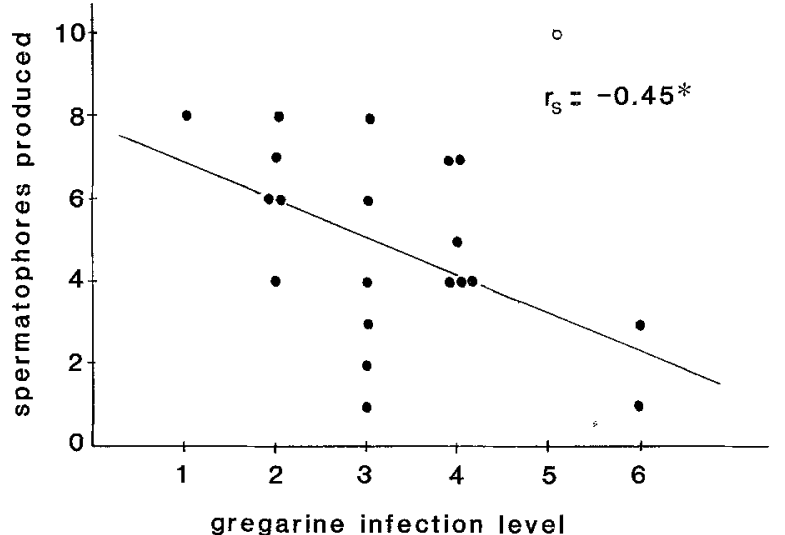

Fig. 4. Number of spermatophores produced in $24 \mathrm{~h}$ by fieldcollected $G$. pennsylvanicus wih different levels of naturally occurring gregarine infections. Infection levels increase in severity with increasing number; see text for detailed description. Regression line and rank correlation statistic shown were calculated omitting the data point indicated by an open circle. ${ }^{*} P<$ 0.05

of the data, however, revealed a single outlier. Regression of spermatophores produced on gregarine infection levels indicated that this individual point had a standardized residual deviation from the line of 2.43. The recalculated correlation without this individual was significantly negative, just as in $G$. veletis (Fig. 4, $P=0.04$ ).

\section{Short-term spermatophore production}

When spermatophore production was monitored every half hour for two hours, males produced an average of $2.21 \pm 0.18$ spermatophores over the trial period. All males produced at least one spermatophore, but only one individual produced four spermatophores. Gregarine levels in these males were not significantly correlated with the number of spermatophores produced $(P=0.20)$.

\section{Spermatophore transfer to multiple females}

All 37 males transferred spermatophores to at least one of the females. By the end of the $12 \mathrm{~h}$, one or more spermatophores were found attached to the genital openings of both females in 18 cases $(49 \%)$, while in 19 cases only one female had received a spermatophore. Two or three spermatophores were transferred to the same female in 19 cases $(51 \%)$, while two males each gave four spermatophores to only one of the females in the jar. In eight of the multiple spermatophore transfers, all spermatophores were given to one female. A spermatophore usually fell off or was removed by the female before she accepted another one, but 
occasionally two spermatophores were strung together at the base of the ovipositor.

During these experiments, females were frequently aggressive toward one another. Kicking, chasing and antenna lashing were all observed, corresponding to the first three aggression levels according to Alexander (1961).

\section{Discussion}

This study suggests both that multiple spermatophore production is an important component of male mating success in $G$. veletis and $G$. pennsylvanicus and that gregarine parasite load is negatively correlated with the ability to produce multiple spermatophores in both species. The latter conclusion supports Hamilton and Zuk's (1982) suggestion that parasites are important in sexual selection, although the manner in which the effect was manifested is different from that originally predicted. Assuming that resistance to the parasites is inherited, females mating repeatedly with the same male may have been favoured by natural selection, because healthy males are more likely to be able to provide several spermatophores in succession. Gregarines are not transmitted directly via contact with an infected host, which means that the benefit to a female mating with a healthy male lies not in her own avoidance of disease, but in the likelihood that she will pass on genes for resistance to her offspring.

Parasite load was not correlated with spermatophore production in the short-term investigation. In this experiment, variation in spermatophore production was small; only one cricket produced four spermatophores and the majority produced two or three. Such low variance may have made statistical detection of any correlation difficult even if one were present. Alternatively, the gregarines' effect may only be noticeable after a male has been with a female for longer than $2 \mathrm{~h}$.

Unlike the situation found in tettigoniid katydids and the cricket Gryllodes supplicans, body size in the two cricket species studied here was unrelated to spermatophore production. G. supplicans and many species of tettigoniids produce large nutritious spermatophylaxes in addition to the spermcontaining spermatophores, and larger males manufacture larger spermatophylaxes, which the females prefer (Gwynne 1982; Sakaluk 1985). The small, simple spermatophore in $G$. veletis and $G$. pennsylvanicus does not afford such opportunities, and the field crickets may be more similar in this respect to the cockroach Diploptera punctata, in which sperm production was unrelated to body size, but dependent on the duration of larval development (Woodhead 1984). Adult male weight in $G$. integer was not correlated with another characteristic potentially important in mating success, the amount of time spent calling (Cade and Wyatt 1984).

Numerous studies have shown that both male and female crickets mate more than once, and that males are capable of producing several spermatophores. Virgin $G$. integer females mated 2-5 times in $6 \mathrm{~h}$ (Sakaluk and Cade 1980), T. commodus females mated an average of 3.3 times in $12 \mathrm{~h}$ (Loher and Rence 1978), and an Anurogryllus arboreus male mated three times with two females in an evening (Walker 1980). Although initial spermatophore replacement times of 15-20 min have been noted in A. domesticus and $G$. integer (Alexander 1961; Sakaluk and Cade 1983), no study before this one has systematically examined variation in maximum spermatophore production capability and its correlates. Loher and Edson (1973) reported that spermatophore formation required a mean of $2 \mathrm{~h}$ in $T$. commodus, but did not systematically deplete males in their experiment. Clearly, some $G$. veletis and $G$. pennsylvanicus males are capable of producing several spermatophores in a $24 \mathrm{~h}$ period, and may repeatedly replace spermatophores in less than half an hour, but others, even under apparently optimal mating conditions, are not.

\section{Relevance of multiple spermatophore production to sexual selection}

The results of three experiments suggest that multiple spermatophore replacement is important to crickets in the field. In the study of spermatophore transfer to more than one female, only $49 \%$ of males left with two females gave spermatophores to both, even though two or three spermatophores were often transferred to the same female, supporting the idea that male ability to produce multiple spermatophores can limit male mating success. Female aggression may also play a role in determining the recipient of spermatophores; because the laboratory situation prevented females from actually displacing each other, an event that may occur in the field, the influence of female behaviour on multiple spermatophore production is as yet unknown.

The simultaneous availability of two or more females could result from the concentration of courtship and mating in the morning noted by French (1986) and corroborated here in the observations of diel song distribution. Spermatophore 
production peaks in the morning as well (Fig. 2). A diel periodicity in spermatophore formation was noted both in $A$. domesticus, where the spermatophore was formed in the light portion of the photoperiod (McFarlane 1968), and in T. commodus, where the spermatophore was formed $1-5 \mathrm{~h}$ before calling began and was lost within a variable time after the cricket stopped singing (Loher 1974). In both of these studies, however, males were isolated from females and spermatophores were not removed, so the relevance of the findings is limited.

The cause and effect relationship between spermatophore production, courtship song, and mating frquency cannot be determined from these results. Lloyd (1981) has suggested that female insects might remain around signalling males for long periods, evaluating characteristics of the signallers and eventually mating with the chosen individual(s). Females of Orchelimum meadow grasshoppers can be observed near calling males for hours or even days before mating (Feaver 1977); it may be that Gryllus females are most phonotactic at night, but wait until morning to mate. On the other hand, spermatophore production may be constrained to the morning by some undetermined aspect of cricket physiology governed by photoperiod. In either case, a concentration of spermatophore production at a particular time of day places a premium on male ability to replace spermatophores relatively quickly.

\section{"Guarding" as a test of male vigour}

The negative correlation between spermatophore production and gregarine load, along with the emphasis on rapid spermatophore replacement discussed above, suggest a new interpretation of male and female behaviours during postcopulatory guarding in crickets. While the advantage to the male of ensuring complete insemination of the female is obvious, why a female should require such monitoring, and how she might benefit by eating a spermatophore before it has released sperm, has not been immediately clear to investigators. Thornhill and Alcock (1983) suggest that early "escape attempts" on the part of recently mated females test the male's dominance by bringing the pair in contact with other, competitor males. This does not explain the female propensity for consuming spermatophores soon after mating, an activity that Acheta domesticus and $G$. integer males were apparently unsuccessful in preventing (Sakaluk and Cade 1980; Sakaluk and Cade 1983).

The male and female behaviour patterns that follow spermatophore transfer may represent, not the male controlling female movements, but the working out of a conflict of interest between the sexes. If a female eats or removes a spermatophore, her mate will increase the number of offspring he sires if he can provide her with another spermatophore, because her fecundity is higher when she is mated more than once (Sakaluk and Cade 1980). The female might benefit by "premature" spermatophore removal in two ways. First, she obtains whatever nutrients or accessory substances are present in the spermatophore (Bentur and Mathad 1975; Loher and Rence 1978; Walker 1980); these are not as substantial as those acquired from other orthopterans such as katydids (Gwynne 1982), but may be present nonetheless. Second, she fertilizes more of her eggs with a male that is vigorous and relatively parasite-free. On the other hand, a male that prevents a female from removing a spermatophore or from leaving before he can manufacture another spermatophore can save the energy required for other matings. How such a conflict of interest is resolved will depend upon the characteristics of the individuals involved.

Acknowledgements. I thank the members of my doctoral committee, R.D. Alexander, W.H. Cade, P.R. Grant, W.G. Holmes, P. Smouse, and especially W.D. Hamilton, for their advice and criticism of the manuscript and during my research. W. Loher also commented on the manuscript, and P. Decker and J.T. Rotenberry provided valuable assistance. My dissertation research was funded by Walker-Hinsdale scholarships from the Museum of Zoology, and by the Division of Biological Sciences, the Horace H. Rackham School of Graduate Studies, and the University of Michigan Biological Station.

\section{References}

Alexander R (1961) Aggressiveness, territoriality, and sexual behaviour in field crickets (Orthoptera:Gryllidae). Behav $17: 130-223$

Alexander RD, Meral GH (1967) Seasonal and daily chirping cycles in the northern spring and fall field crickets, Gryllus veletis and $G$. pennsylvanicus. Ohio J Science 67:200-209

Anderson RM, May RM (1981) The population dynamics of microparasites and their invertebrate hosts. Phil Trans R Soc Lond B-291:451-524

Bentur JF, Mathad SB (1975) The dual role of mating in egg production and survival in the cricket, Plebiogryllus guttiventris Walker. Experientia 31:539-540

Bucher GE (1959) Bacteria of grasshoppers of western Canada, III. Frequency of occurrence, pathogenicity. J Insect Pathol $1: 391-405$

Cade WH, Wyatt DR (1984) Factors affecting calling behaviour in field crickets, Teleogryllus and Gryllus (age, weight, density and parasites). Behav 88:61-75

Dunkel FV, Boush GM (1969) Effect of starvation on the black carpet beetle, Attagenus megatoma, infected with the eugregarine Pyxinia frenzeli. J Invert Pathol 14:50-62

Eshel I, Hamilton WD (1984) Parent-offspring correlation in fitness under fluctuating selection. Proc R Soc Lond B 122:1-14 
Feaver M (1977) Aspects of the behavioral ecology of three species of Orchelimum (Orthoptera: Tettigoniidae). $\mathrm{PhD}$ thesis, University of Michigan, Ann Arbor

French W (1986) Male reproductive competition in the field crickets Gryllus veletis and G. pennsylvanicus. MSc thesis, Brock University, St. Catharines, Ontario

Gwynne DT (1982) Mate selection by female katydids (Orthoptera: Tettigoniidae, Conocephalus nigropleurum). Anim Behav 30:734-738

Gwynne DT, Morris GK (eds) (1983) Orthopteran mating systems: sexual competition in a diverse group of insects. Westview Press, Boulder, Colorado

Hamilton WD (1982) Pathogens as causes of genetic diversity in their host populations. In: Anderson RM, May RM (eds) Population biology of infectious disease agents. Dahlem Konferenz 1982. Verlag Chemie, Weinheim, pp 269-296

Hamilton WD, Zuk M (1982) Heritable true fitness and bright birds: a role for parasites? Science 218:384-387

Harry OG (1970) Gregarines: their effect on the growth of the desert locust (Schistocerca gregaria). Nature 225:964-966

Kudo RR (1954) Protozoology, 4th edn. Thomas, Springfield, I11

Lloyd JE (1981) Sexual selection: individuality, identification and recognition in a bumblebee and other insects. Fla Entom 64:89-118

Lloyd JE, Pace AE (1975) Seasonality in northern field crickets. Fla Entom 58:31-32

Loher W (1974) Circadian control of spermatophore formation in the cricket Teleogryllus commodus Walker. J Insect Physiol 20:1155-1172

Loher W, Edson K (1973) The effect of mating on egg production and release in the cricket Teleogryllus commodus Walker. Entomologia exp et appl 16:483-490
Loher W, Rence B (1978) The mating behavior of Teleogryllus commodus (Walker) and its central and peripheral control. Z Tierpsychol 46:225-259

McFarlane JE (1968) Diel periodicity in spermatophore formation in the house cricket, Acheta domesticus (L.). Can J Zool 46:695-698

Sakaluk SK (1985) Spermatophore size and its role in the reproductive behaviour of the cricket, Gryllodes supplicans (Orthoptera: Gryllidae). Can J Zool 63:1652-1656

Sakaluk SK, Cade WH (1980) Female mating frequency and progeny production in singly and doubly mated house and field crickets. Can J Zool 58:404-411

Sakaluk SK, Cade WH (1983) The adaptive significance of female multiple matings in house and field crickets. In: Gwynne DT, Morris GK (eds) Orthopteran mating systems: sexual competition in a diverse group of insects. Westview Press, Boulder, Col

Smith RL (1984) (ed) Sperm Competition and the Evolution of Animal Mating Systems. Academic Press, New York

Thornhill R, Alcock J (1983) The evolution of insect mating systems. Harvard University Press, Cambridge, Mass

Walker TJ (1980) Reproductive behavior and mating success of male short-tailed crickets: differences within and between demes. Evol Biol 13:219-260

Woodhead AP (1984) Effect of duration of larval development on sexual competence in young adult male Diploptera punctata. Physiol Entomol 9:473-477

Zuk M (1987a) Seasonal and individual variation in gregarine parasite levels in the field crickets Gryllus veletis and $G$. pennsylvanicus. Ecol Entomol (in press)

Zuk M (1987b) The effects of gregarine parasites on longevity, weight loss, fecundity and developmental time in the field crickets Gryllus veletis and G. pennsylvanicus. Ecol Entomol (in press) 